\title{
A new case of de novo 19p13.2p13.12 deletion in a girl with overgrowth and severe developmental delay
}

\author{
Abdelhafid Natiq ${ }^{1,3^{*}}$, Siham Chafai Elalaoui ${ }^{1,2}$, Sevrine Miesch ${ }^{4}$, Celine Bonnet ${ }^{4}$, Philippe Jonveaux ${ }^{4}$, \\ Saaïd Amzazi ${ }^{3}$ and Abdelaziz Sefiani, ${ }^{1,2}$
}

\begin{abstract}
Background: We report clinical and molecular cytogenetic characterization of a 2 year-old girl with 19p13.2p13.12 microdeletion and compare her clinical features with those of three other patients reported before.

Result: Array comparative genomic hybridization $(\mathrm{aCGH})$ revealed in the present patient a de novo microdeletion of $1.45 \mathrm{Mb}$ within 19p13.2p13.12. The deletion includes seven OMIM genes: MAN2B1, RNASEH2A, KLF1, GCDH, NFIX, CACNATA and CC2D1A.

Discussion: The present case and three other patients with partially overlapping 19p13 microdeletion share the following features: psychomotor and language delay, intellectual disability, seizures, hypotonia, skeletal anomalies and facial dysmorphism. The smallest region of overlapping between all four reported patients is around $300 \mathrm{~kb}$ and spans only two genes: NFIX and CACNATA. Their haploinsufficincy could be the base for the phenotype -genotype correlation.
\end{abstract}

Keywords: Overgrowth, Psychomotor delay, 19p13.2p13.12 deletion, Array comparative genomic hybridization

\section{Background}

Array comparative genomic hybridization (aCGH) has allowed for identification of the underlying molecular bases for numerous patients with multiple congenital anomalies. De novo microdeletion 19p13 detected by aCGH is rarely reported [1-4]. However, all yet known patients had intellectual disability and multiple congenital anomalies.

We report clinical and molecular cytogenetic characterization of a 2 year-old girl with a $19 \mathrm{p} 13.2$ to 19p13.12 microdeletion and compare her clinical features with those of three other patients $[1,2,4]$. The phenotype is mainly characterized by psychomotor and language delay, intellectual disability, seizures, hypotonia, skeletal anomalies and facial dysmorphism. The shortest region of overlap (SRO) extending for about

\footnotetext{
* Correspondence: abdelnat@yahoo.fr

'Département de Génétique Médicale, Institut National d'Hygiène, Rabat, Morocco

${ }^{3}$ Faculté des Sciences de Rabat, Université Mohamed V Agdal, Rabat,

Morocco

Full list of author information is available at the end of the article
}

$300 \mathrm{~Kb}$ between the four cases contains candidate genes responsible for their common phenotype (severe developmental delay, seizures, and skeletal anomalies). This microdeletion encompasses seven OMIM genes, among which two (NFIX and CACNA1A) could be the candidate genes for the genotype-phenotype relationship.

\section{Case presentation \\ Case report}

The female patient was born at 36 weeks of gestational age to Moroccan consanguineous parents (first degree) with non-contributive familial history. She was referred to genetic consultation for suspicion of Angelman syndrome. She is the fifth liveborn to a 44-year-old mother and 55-year-old father. The mother was followed for chronic myeloid leukemia and was taking Imatinib during her pregnancy (400 mg/day). Still, pregnancy was without reported complications. Birth weight and length 
were $2,500 \mathrm{~g}$ and $42 \mathrm{~cm}$ respectively (both $<3 \mathrm{rd}$ percentile), head circumference was $31 \mathrm{~cm}$ (50th percentile). She had neonatal hypotonia and seizures since her birth. At clinical examination at fifteen months of age, her weight was $12 \mathrm{~kg}$ (>95th centile), and her head circumference $52 \mathrm{~cm}$ ( $>95$ th centile). She had severe axial hypotonia and was unable to hold her head or sit down in addition to absent speech. She also had facial dysmorphism including frontal bossing, down slanting palpebral fissures, microstomia, long philtrum, prognathia, anteverted nostrils, low-set ears, short neck (Figure 1) and also bilateral clinodactyly of the fifth finger.

At 2 years and 3 months her length was $97 \mathrm{~cm}$ (>95th centile), weight $15 \mathrm{~kg}$ (95th centile), and head circumference $52 \mathrm{~cm}$ (>95th centile). She was still hypotonic, unable to hold her head or to sit down, and with absent speech. The cerebral MRI showed bilateral frontal cortical atrophy. The EEG showed epileptiform focal abnormalities disorganized background rythm of slow $(2-3 \mathrm{~Hz})$ waves.

\section{Methods}

Peripheral blood was collected from the patient and her parents. Informed consent was obtained from the patient's parents prior to implementation of the genetic studies.

\section{Cytogenetics analysis}

Cytogenetics studies were performed on metaphase chromosome preparations obtained from phytohemagglutinin stimulated lymphocyte cultures according to standard procedures. Chromosome analysis was carried applying RHG banding at a 400-band level as previously reported and according to the International System for Human Cytogenetic: Nomenclature ISCN $2013[5,6]$.

\section{DNA samples}

DNA was extracted from whole blood using the QIAmp DNA Kit (QIAGEN) according to the manufacturer's instructions.

\section{Methyl PCR}

Methyl PCR was performed with Epitect Bisulfite Kit and EpiTect MSP kit according to the manufacturer's instructions (QIAGEN).

\section{Array-based comparative genomic hybridization}

aCGH was carried out using $180 \mathrm{~K}$-oligonucleotide array (Agilent, San Clara, CA) with an average resolution of about $25 \mathrm{~kb}$, the procedure for DNA digestion and hybridization were performed according to the manufacturer's instruction. For analysis of the result two databases were used respectively for the chromosomal localization: UCSC genome browser (http://genome.UCSC.edu) and for polymorphism control: database of genomic variants (http://dgv.tcag.ca/).

\section{Fluorescent in-situ hybridization (FISH) analysis}

FISH was performed on PHA-stimulated peripheral blood lymphocytes obtained from patient and both parents. BAC RP11-782D11 (located in 19p13.2p13.13) and CTD-2265021 (19q subtelomeric) probes obtained from CHORI (Oakland, CA) were used according standard protocols.

\section{Results}

The karyotype was normal and presence of Angelman syndrome was excluded by methylation specific PCR (MSPCR) (data not shown). In the absence of any etiological diagnosis, array-CGH analysis identified a $1.45 \mathrm{Mb}$ deletion at $19 \mathrm{p} 13.2 \mathrm{p} 13.12$ in the patient

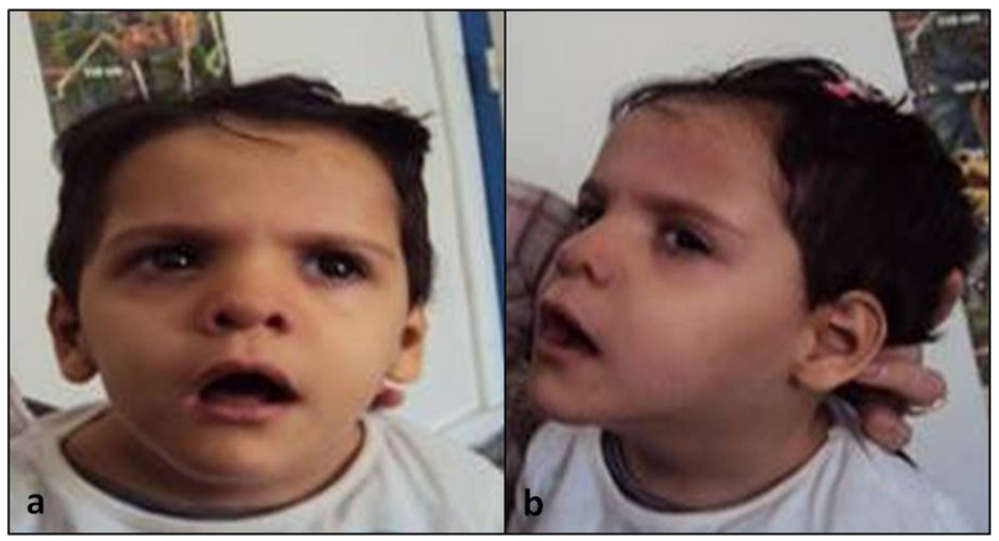

Figure 1 Photographs of the patient at age of 2 years and 3 months, frontal (a) and lateral (b) view. Note the tall forehead, anteverted nares, thin upper lip, anteverted ears and long philtrum. 


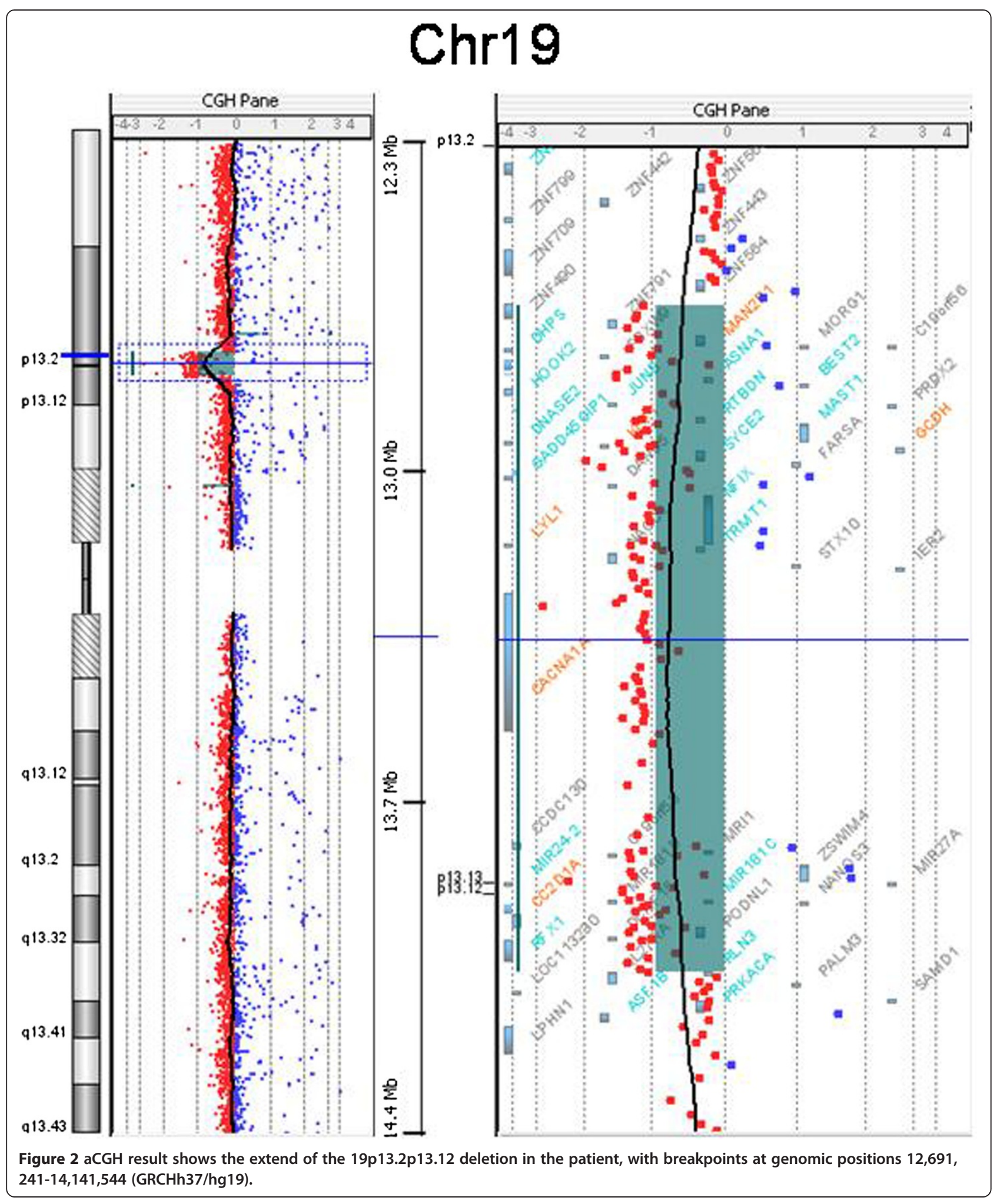


(Figure 2): 46,XX.arr[hg19]19p13.2p13.12(12,691,24114,141,544)x1, GRCHh37/hg19. The deleted region included 44 genes. Except for polymorphic regions, no copy number alterations were observed in other chromosomes. Because of the necessity to compare with other cases we reanalyzed with the hg 18 Build 36 version and the breakpoints were: 12,552,241-14,002,544. (NCBI36/ hg18) The deletion was confirmed by FISH analysis (Figure 3), and is considered to be do novo since neither parent carries the deletion (data not shown). We report here, a $1.45 \mathrm{Mb}$ microdeletion 19p13.2p13.12 in a child with overgrowth and multiple congenital anomalies. This deletion encompasses 44 genes from which only seven (MAN2B1,RNASEH2A, KLF1, GCDH, NFIX, CAC$N A 1 A$, and $C C 2 D 1 A$ ) were OMIM genes and reportedly as involved in human diseases.

\section{Conclusion}

Microdeletion 19p13 has been rarely reported in the literature [1-4]. This region has a high gene density and this is most likely the reason why deletions in this region are associated with a severe phenotype. Actually with the development of the chromosomal microarray analysis technology there has been a little increase in the number of reported cases with a microdeletion 19p13 [4]. The clinical features common to our patient and the cases reported before $[1,2,4]$ are psychomotor and language delay, intellectual disability, seizures, hypotonia, skeletal anomalies and facial dysmorphism (Table 1).

The four cases share approximately a $300-\mathrm{kb}$ shortest region of overlap (SRO) including NFIX1 and CAC$N A 1 A$ genes (Figure 4). This region had never been described as a copy number polymorphism (CNP) in the database of genomic variants (http://dgv.tcag.ca). NFIX [Nuclear Factor IX (CCAAT-binding transcription factor)] (OMIM 164005), a member of the nuclear factor I (Nfi) family of transcription factors, is highly expressed in the developing mouse brain and an essential gene for normal brain and skeletal development [5,7]. NFIX deficient mice show enlargement of the lateral and third brain ventricles and partial agenesis of the corpus callosum [7,8]. Our patient and the case of Auvin et al. [2] showed advanced bone age. Lysy et al. [1] reported craniosynostosis and kyphosis in their patients. The phenotype associated with NFIX haploinsufficiency may occur with variable penetrance because the third case reported by Bonaglia et al. [4] does not show any of these malformations. Other study demonstrates that NFIX deletion and its nonsense mutation (c.179T_C (p.Leu60Pro) and c.362G_C (p.Arg121Pro)) are associated with a novel clinically recognizable overgrowth

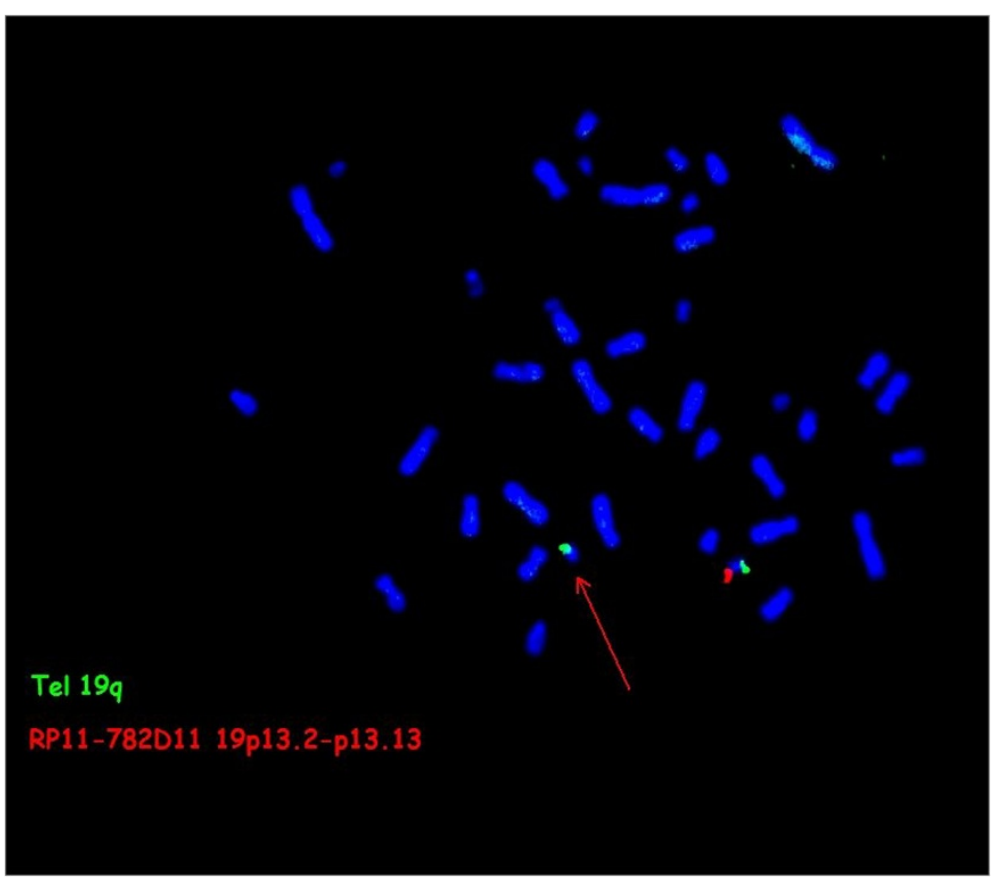

Figure 3 FISH analysis of the 19p13.2-p13.12 deletion. Spectrum-orange labeled BAC clone RP11-782D11 and spectrum-green labeled 19q subtelomeric (CTD-2265021) probe (Tel 19q) used for identification of chromosomes 19. Arrow indicate the absence of orange signal on chromosome del(19)(p13.2 13.12p13.2 13.12). 
Table 1 Summary of clinical features and cytogenetic characteristics of the reported patients with 19p13 deletion overlapping with our patient

\begin{tabular}{|c|c|c|c|c|c|}
\hline Patient & Present patient & Bonaglia et al. [4] Patient 3 & Auvin et al. [2] & Lysy et al. [1] & Clinical score \\
\hline Gender & Female & Male & Male & Female & \\
\hline Chrom.region & 19p13.2-p13.12 & 19p13.13-p13.12 & 19p13.13 & 19p13.2-p13.13 & \\
\hline Deletion size Mb & $1.45 \mathrm{Mb}$ & $1.5 \mathrm{Mb}$ & $664 \mathrm{~Kb}$ & $3 \mathrm{Mb}$ & \\
\hline Position (hg18) & $12.55-14.00$ & $12.87-14.15$ & $12.61-13.28$ & $10.25-13.18$ & \\
\hline \multicolumn{6}{|l|}{ At birth } \\
\hline Weight & $<3 r d$ & $<3 r d$ & Normal & $-2 S D$ & \\
\hline Length & $<3 r d$ & $<3 r d$ & Normal & $-2 S \mathrm{~S}$ & \\
\hline OFC & 50th & 10-15th & Normal & $-2 S D$ & \\
\hline \multicolumn{6}{|l|}{ At last evaluation } \\
\hline Age & $2^{3 / 12}$ years & 7 years & 2 years & $3^{8 / 12}$ years & \\
\hline Weight & $>95$ th & 50th & $+2 S \mathrm{D}$ & $-2 S D$ & \\
\hline Length & 95 th & 75th & $+3 S D$ & $-2 \mathrm{SD}$ & \\
\hline OFC & 95 th & 50th & $+2,5 \mathrm{SD}$ & $-2 S D$ & \\
\hline \multicolumn{6}{|l|}{ Clinical features } \\
\hline Hypotonia & Severe & + & + & + & $4 / 4$ \\
\hline Psychomotor delay & + & Moderate- severe & + & + & $4 / 4$ \\
\hline Language delay & + & + & + & + & $4 / 4$ \\
\hline Seizure/EEG anomalies & + & + & + & + & $4 / 4$ \\
\hline Hearing loss & - & Bilateral conductive & - & Bilateral threshold $60 \mathrm{~dB}$ & $2 / 4$ \\
\hline Skeletal & Advanced bone age & Scoliosis & Advanced bone age & $\begin{array}{l}\text { Craniocynostosis with left } \\
\text { spleno-orbital dysplasia }\end{array}$ & $4 / 4$ \\
\hline Extremities & Clinodactyly V & $\begin{array}{l}\text { ClinodactylyV right hand, left I and II } \\
\text { toes overlapping bracydactyly }\end{array}$ & - & - & $2 / 4$ \\
\hline \multicolumn{6}{|l|}{ Facial features } \\
\hline Brachycephaly & + & + & - & - & $2 / 4$ \\
\hline Philtrum & long & long & - & - & $2 / 4$ \\
\hline Nose & Anteverted nares & Anteverted nares & Flat & - & $3 / 4$ \\
\hline Ocular anomalies & Strabismus & - & - & strabismus & $2 / 4$ \\
\hline
\end{tabular}




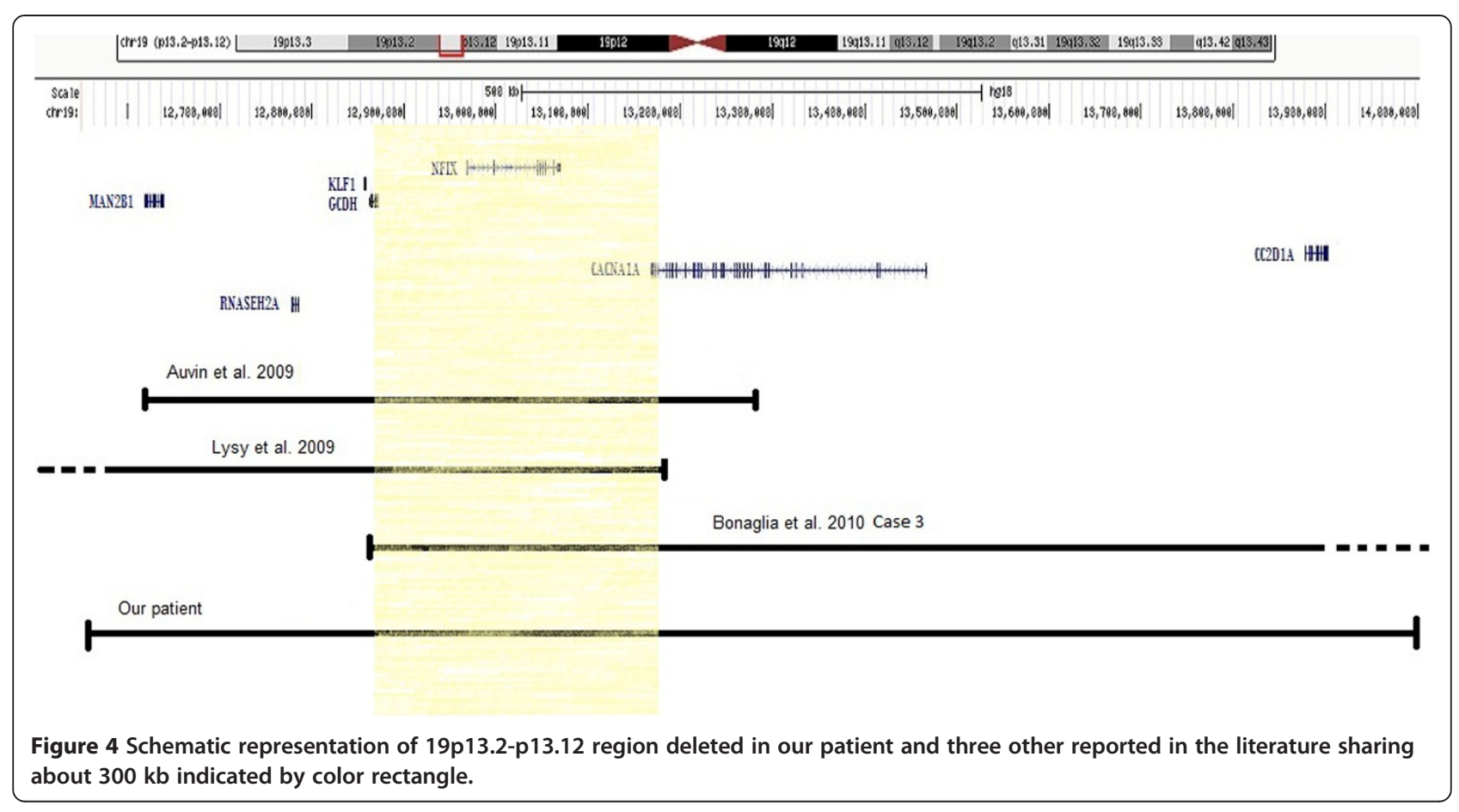

syndrome like Marshall-Smith and Sotos like Syndrome [8,9]. The CACNA1A gene (calcium channel alpha 1A subunit) (OMIM 601011) is involved with the voltage-dependant $\mathrm{Ca} 2+$ channels and has been reported in association with epilepsy and chronic neurological disorders, haploinsufficiency of this gene has been suggested to be responsible for epilepsy and infantile spasms $[10,11]$. Recently Marangi et al. report a deletion 19p12.13-p13.13 encompassing the first exon of the CACNA1A in a patient with EEG focal anomalies and suffering from febrile seizures [12]. In addition CACNA1A gene has been involved in the occurrence of developmental delay $[13,14]$. We suggest that $C A C$ $N A 1 A$ gene deletion is likely responsible for the epileptic seizures in our patient.

In addition through this case report, we want to focus on the importance of a (aCGH) as a first-tier diagnostic step for patients with developmental disabilities and/or multiples congenital anomalies as reported by several scientific papers [15-18].

This report gives more information for the recently identified 19p13 deletion syndrome and clarifies the clinical implication of genes in the involved chromosomal region. Also, our paper may contribute to a better understanding of the genotype-phenotype correlation in cases with deletion in 19p13 and particularly in the involvement of NFIX and CACNA1A genes in overgrowth, epilepsies and developmental delay.

\section{Consent}

Written informed consent was obtained from the patient's parents for publication and accompanying images of this case report. A copy of the written consent is available for review by the Editor-in-Chief of this journal.

\section{Competing interest}

The authors declare that they have no competing interests.

\section{Authors' contribution}

AN carried out the molecular genetic studies and drafted the manuscript. SCE helped to draft the manuscript, SM, CB and PJ participated in the molecular genetic studies and helped to draft the manuscript, SA participated in the design of the study and AS helped to draft the manuscript. All authors read and approved the final manuscript.

\section{Acknowledgements}

The authors would like to gratefully acknowledge the patient and her parents for their collaboration.

\section{Author details}

'Département de Génétique Médicale, Institut National d'Hygiène, Rabat, Morocco. ${ }^{2}$ Centre de génomique humaine, Faculté de médecine et de pharmacie, Université Mohammed V, Rabat, Morocco. ${ }^{3}$ Faculté des Sciences de Rabat, Université Mohamed V Agdal, Rabat, Morocco.

${ }^{4}$ Laboratoire de Génétique Médicale, Centre Hospitalier Universitaire, Nancy, France.

Received: 26 March 2014 Accepted: 21 May 2014

Published: 5 June 2014 


\section{References}

1. Lysy PA, Ravoet M, Wustefeld S, Bernard P, Nassogne MC, Wyns E, Sibille C: A new case of syndromic craniosynostosis with cryptic 19p13.2-p13.13 deletion. Am J Med Genet A 2009, 149A(11):2564-2568.

2. Auvin S, Holder-Espinasse M, Lamblin MD, Andrieux J: Array-CGH detection of a de novo 0.7-Mb deletion in 19p13.13 including CACNA1A associated with mental retardation and epilepsy with infantile spasms. Epilepsia 2009, 50(11):2501-2503.

3. Jensen DR, Martin DM, Gebarski S, Sahoo T, Brundage EK, Chinault AC, Otto EA, Chaki M, Hildebrandt F, Cheung SW, Lesperance MM: A novel chromosome 19p13.12 deletion in a child with multiple congenital anomalies. Am J Med Genet A 2009, 149A(3):396-402.

4. Bonaglia MC, Marelli S, Novara F, Commodaro S, Borgatti R, Minardo G, Memo L, Mangold E, Beri S, Zucca C, Brambilla D, Molteni M, Giorda R, Weber RG, Zuffardi O: Genotype-phenotype relationship in three cases with overlapping 19p13.12 microdeletions. Eur J Hum Genet 2010, 18(12):1302-1309.

5. Simons A, Shaffer $L G$, Hastings RJ: Cytogenetic nomenclature: changes in the ISCN 2013 compared to the 2009 edition. Cytogenet Genome Res 2013, 141:1-6.

6. Aboussair N, Jaouad IC, Dequaqui SC, Sbiti A, Elkerch F, Yahya B, Natiq A Sefiani A: Cytogenetic analysis of 5572 patients referred for suspected chromosomal abnormalities in Morocco. Genet Test Mol Biomarkers 2012. 16(6):569-573.

7. Driller K, Pagenstecher A, Uhl M, Omran H, Berlis A, Grunder A, Sippel AE: Nuclear factor I $\mathrm{X}$ deficiency causes brain malformation and severe skeletal defects. Mol Cell Biol 2007, 27(10):3855-3867.

8. Malan V, Rajan D, Thomas S, Shaw AC, Louis Dit Picard H, Layet V, Till M, van Haeringen A, Mortier G, Nampoothiri S, Puselijí S, Legeai-Mallet L, Carter NP, Vekemans M, Munnich A, Hennekam RC, Colleaux L, Cormier-Daire V: Distinct effects of allelic NFIX mutations on nonsense-mediated mRNA decay engender either a Sotos-like or a Marshall-Smith syndrome. Am J Hum Genet 2010, 87(2):189-198.

9. Yoneda Y, Saitsu H, Touyama M, Makita Y, Miyamoto A, Hamada K, Kurotaki N, Tomita H, Nishiyama K, Tsurusaki Y, Doi H, Miyake N, Ogata K, Naritomi K, Matsumoto N: Missense mutations in the DNA-binding/dimerization domain of NFIX cause Sotos-like features. J Hum Genet 2012, 57(3):207-211. HYPERLINK "http://www.ncbi.nlm.nih.gov/pubmed?term=Matsumoto\%20N\% 5BAuthor\%5D\&cauthor=true\&cauthor_uid=22301465.

10. Beauvais K, Cave-Riant F, De Barace C, Tardieu M, Tournier-Lasserve E, Furby A: New CACNA1A gene mutation in a case of familial hemiplegic migraine with status epilepticus. Eur Neurol 2004, 52(1):58-61.

11. Kors EE, Melberg A, Vanmolkot KR, Kumlien E, Haan J, Raininko R, Flink R, Ginjaar HB, Frants RR, van den Ferrari MD, Maagdenberg AM: Childhood epilepsy, familial hemiplegic migraine, cerebellar ataxia, and a new CACNA1A mutation. Neurology 2004, 63(6):1136-1137. HYPERLINK "http:// www.ncbi.nIm.nih.gov/pubmed?term=van\%20den\%20Maagdenberg\%20AM\% 5BAuthor\%5D\&cauthor=true\&cauthor_uid=15452324" HYPERLINK "http://www. ncbi.nIm.nih.gov/pubmed?term=van\%20den\%20Maagdenberg\%20AM\% 5BAuthor\%5D\&cauthor=true\&cauthor_uid=15452324.

12. Marangi G, Orteschi D, Vigevano F, Felie J, Walsh CA, Manzini MC, Neri G: Expanding the spectrum of rearrangements involving chromosome 19: a mild phenotype associated with a 19p13.12-p13.13 deletion. Am J Med Genet A 2012, 158A(4):888-893.

13. Vahedi K, Denier C, Ducros A, Bousson V, Levy C, Chabriat H, Haguenau M, Tournier-Lasserve E, Bousser MG: CACNA1A gene de novo mutation causing hemiplegic migraine, coma, and cerebellar atrophy. Neurology 2000, 55(7):1040-1042.

14. Guerin AA, Feigenbaum A, Donner EJ, Yoon G: Stepwise developmental regression associated with novel CACNA1A mutation. Pediatr Neurol 2008, 39(5):363-364.

15. Miller DT, Adam MP, Aradhya S, Biesecker LG, Brothman AR, Carter NP, Church DM, Crolla JA, Eichler EE, Epstein CJ, Faucett WA, Feuk L, Friedman JM, Hamosh A, Jackson L, Kaminsky EB, Kok K, Krantz ID, Kuhn RM, Lee C, Ostell JM, Rosenberg C, Scherer SW, Spinner NB, Stavropoulos DJ, Tepperberg JH, Thorland EC, Vermeesch JR, Waggoner DJ, Watson MS, Martin CL, Ledbetter $\mathrm{DH}$ : Consensus statement: chromosomal microarray is a first-tier clinical diagnostic test for individuals with developmental disabilities or congenital anomalies. Am J Hum Genet 2010, 86(5):749-764. HYPERLINK "http://www.ncbi. nIm.nih.gov/pubmed?term=Vermeesch\%20JR\%5BAuthor\% 5D\&cauthor=true\&cauthor_uid=20466091.
16. Regier DA, Friedman JM, Marra CA: Value for money? Array genomic hybridization for diagnostic testing for genetic causes of intellectual disability. Am J Hum Genet 2010, 86(5):765-772.

17. Yu S, Bittel DC, Kibiryeva N, Zwick DL, Cooley LD: Validation of the Agilent 244K oligonucleotide array-based comparative genomic hybridization platform for clinical cytogenetic diagnosis. Am J Clin Pathol 2009, 132(3):349-360.

18. Xiang B, Zhu H, Shen Y, Miller DT, Lu K, Hu X, Andersson HC, Narumanchi TM, Wang Y, Wu BL, Li P, Li MM, Chen TJ, Fan YS: Genomewide oligonucleotide array comparative genomic hybridization for etiological diagnosis of mental retardation: a multicenter experience of 1499 clinical cases. $J \mathrm{Mol}$ Diagn 2010, 12(2):204-212.

doi:10.1186/1755-8166-7-40

Cite this article as: Natiq et al:: A new case of de novo 19p13.2p13.12 deletion in a girl with overgrowth and severe developmental delay. Molecular Cytogenetics 2014 7:40.

\section{Submit your next manuscript to BioMed Central and take full advantage of:}

- Convenient online submission

- Thorough peer review

- No space constraints or color figure charges

- Immediate publication on acceptance

- Inclusion in PubMed, CAS, Scopus and Google Scholar

- Research which is freely available for redistribution 